\title{
MORPHOLOGY AND MECHANICAL PROPERTIES OF POLYPROPYLENE-WOOD FLOUR COMPOSITES
}

\author{
D. Dobreva, ${ }^{*}$ S. Nenkova, St. Vasileva
}

The microstructure and mechanical properties of polymer composites based on polypropylene and wood flour modified with monochloroacetic acid were investigated. Scanning electron microscopy and wide-angle X-ray diffraction were used as methods to probe the composite microstructures, while the tensile test was used to measure the physical strength. The wood flour modification was performed at different levels of monochloroacetic acid, ranging from 0.01 to $1 \mathrm{~mol}$, while the modified wood flour was used as filler for polypropylene at 10, 20 and $30 \mathrm{wt} . \%$. It was found that increasing the monochloroacetic acid fraction influences the microstructure of the composites and leads to more homogeneous products. The introduction of non-modified wood flour decreases the polypropylene crystallization degree, but it improves after introduction of monochloroacetic acid. Physical-mechanical tests showed positive effects on tensile tests and Charpy notched impact strength. The new composites appear to be promising materials for construction purposes.

Keywords: Morphology; Polypropylene-wood flour composites; Monochloroacetic acid; Mechanical Properties; Modification

Contact information: Department of Polymer Engineering, University of Chemical Technology and Metallurgy, $8 \mathrm{Kl}$. Ohridski Blvd., 1756 Sofia, Bulgaria; *Corresponding author: Tel.: +359 2 8685493; fax: +3592 8685488. E-mail address: dobromira.dobreva@gmail.com

\section{INTRODUCTION}

Over the last few years, wood-fiber thermoplastic composites have received considerable attention from the wood and plastic industries. Although wood flour has been used as filler for thermosetting polymers for a long time, wood fibers or cellulose fillers are being increasingly used nowadays to reinforce thermoplastics for development of new applications. Wood flour is an attractive filler for thermoplastic polymers mainly because of its low cost and large availability (Nunez et al. 2002; Coutinho et al. 2004; Michler 1999; Marcovich et al. 1998a; Park and Balatinecz 1997a; Hristov et al. 2004). Several research groups reported on the use of wood flour as potential fillers for synthetic polymers (Marcovich et al. 1998b; Wu et al. 2000; Park and Balatinecz 1997b; Toriz et al 2002; Qiu et al. 2005; Shibata et al. 2005). Park and Balatinecz have investigated the effect of flour-surface treatment on the microstructure of wood flour filled polyolefins. In those studies, the composites were predominantly processed by extrusion and compression molding. To obtain a composite based on non polar thermoplastics with competitive final properties, it is necessary to achieve a good interface between filler and matrix, generally realized by the modification of the filler surface (Thielemans and Wool 2005; Toriz et al. 2001; Toriz et al. 2004; Albano et al. 2004; Tacterajvidi and Ebrahimi 2003; Oksman and Clemons 1998). 
For improving the rheological properties it is necessary to optimize the interface between the filler and the polypropylene matrix using monochloroacetic acid for modifycation of wood flour (Dobreva et al 2005). In earlier investigations, carboxymethylation of wood flour by an etherification reaction at room temperature with monochloroacetic acid was demonstrated (Dobreva et al 2004; Kishi and Shiraiski 1986; Tan and Yu 1997; Bazarnova et al. 2004). The carboxymethylated material enhances the polymer-philic character of the filler so that such composites materials are obtained much more easily.

The main purpose of the current work was to investigate the structural evolution and morphological changes of polymer composite materials from polypropylene and wood flour, modified with different molar contents of monochloroacetic acid. In addition we have determined specific mechanical properties of the new materials for a more detailed characterization.

\section{EXPERIMENTAL}

\section{Materials}

The experiments were carried out with wood flour obtained from coniferous wood with particle size of about $140 \mu \mathrm{m}$, specific volume of $8 \mathrm{dm}^{3} / \mathrm{kg}$ and moisture content of 5 wt.\%. Monochloroacetic acid, used as the modifying reagent, was purchased from MERCK (purity $>99 \%$ ) with a melting interval from 60 to $63^{\circ} \mathrm{C}$. Wood flour modifycation was realized with monochloroacetic acid content ranging from 0.01 to 1 mole.

Isotactic polypropylene with trade mark BUPLEN 7523 - LUKOIL - Burgas with flow index of $4 \mathrm{~g} / 10 \mathrm{~min}$ was used for obtaining polymer composites. Wood flour is added to polypropylene in quantities of 10, 20 and $30 \mathrm{wt} . \mathrm{\%}$. Some polymer composites included 5\% compatibilizer Fusabond PMD353D Dupont (CA, USA).

\section{Techniques}

The chemical modification of wood flour is conducted with different contents of monochloroacetic acid ranging from 0.01 up to 1 mole by a suspensional method. The alkylation mixture consists of monochloroacetic acid and sodium base. Modified wood flour is chemically modified completely after approximately 48 hours. Before using the wood flour samples, they were flushed thoroughly with methyl alcohol. By this we obtained carboxymethylated wood flour (CMWF) without any contamination from sodium chloride or other chloride-containing materials.

The polypropylene, wood flour and the coupling agent MAPP (maleated polypropylene) were mixed in a Leistritz MICRO18 co-rotating twin-screw extruder (screw diameter $35 \mathrm{~mm}$ ). The barrel temperatures were: $190^{\circ} \mathrm{C}$ for zone $1,180^{\circ} \mathrm{C}$ for zone 2 and $185^{\circ} \mathrm{C}$ for zones $3-6$ and $180^{\circ} \mathrm{C}$ at the last zone. The frequency of the screw rotation was $300 \mathrm{~min}^{-1}$ and the material output was $0.9 \mathrm{~kg} / \mathrm{h}$. The product temperature was $186^{\circ} \mathrm{C}$. The extruder strands were then cooled in a water slide system, pelletized, and dried at $105^{\circ} \mathrm{C}$. The compounded pellets were injection molded using a conventional BOY 22A reciprocating screw injection molder into standard DIN test specimens.

The mechanical behavior of composites was examined by tensile and fracture

tests. Tensile tests were performed according to DIN 53834 (samples thickness $4 \mathrm{~mm}$ ) 
by using a Zwick machine (model 1445) at a crosshead speed of $50 \mathrm{~mm} / \mathrm{min}$. From the stress-strain curves percent elongation at break $\left(\varepsilon_{\mathrm{b}}\right)$ and E-modulus were determined.

Fracture tests were carried out on a Charpy instrument at an impact speed of 1 $\mathrm{mm} / \mathrm{s}$. For this test samples (in the form of small bars with dimensions $80 \times 10 \times 4 \mathrm{~mm}$ ) are notched as follows: first, a blunt notch was produced by using a machine with shaped tool, and then a sharp notch of $\sim 2 \mathrm{~mm}$ depth was made by a razor blade fixed to a micrometric apparatus.

Scanning electron microscopy (SEM) observations of polypropylene and polymer composites were made with a JEOL electron microscope (Model JSM 6400). The samples were fractured after cooling in liquid nitrogen and the freshly fractured surfaces were coated with thin Au layers for elimination of charge effects in the microscope.

The samples for wide-angle X-ray diffraction were carefully homogenized by grinding the samples in an analytical mill cooled with liquid nitrogen. X-ray scattering curves of the powder samples were measured by means of a two-circle-X-ray diffractometer (Bruker-AXS) in symmetrical transmission technique using monochromized (Ge(111)-monochromator) $\mathrm{CuK}_{\alpha}$-radiation $(40 \mathrm{kV}, 30 \mathrm{~mA})$. The angular range was $3-16^{\circ}(\theta)$ and the step width was $0.2^{\circ}(\theta)$.

The scattering curves were corrected with regard to background scattering, absorption, incoherent scattering and were normalized to electron units. The corrected and normalized Wide Angle X-ray Scattering (WAXS) curves were used to determine a degree of crystallinity, $\mathrm{x}_{\mathrm{c}}$, and a lattice disorder parameter $\mathrm{k}$ according to the Ruland/Vonk method (Ruland 1961).

\section{RESULTS AND DISCUSSION}

Figure 1 illustrates the impact strength by Charpy analysis for each composition. The poorer mechanical properties of the unmodified polypropylene wood flour composite are due to poor adhesion between the polypropylene matrix and wood flour.

The concentration of monochloroacetic acid in the wood flour was found to have a significant effect on the microstructure; more specifically, on the deformation mechanism and mechanical properties of the composites. Improvements in impact strength were determined in all samples including 10 and $20 \mathrm{wt} .-\%$ modified filler. An exception to this is the material modified with 1 mole $\mathrm{NaOH}$ and 1 mole $\mathrm{ClCH}_{2} \mathrm{COOH}$, and $5 \%$ compatibilizer. The impact energy was remarkably enhanced with the addition of 10 and 20 wt.-\% wood flour to which was added $1 \mathrm{~mol}$ of $\mathrm{NaOH}$ and $1 \mathrm{~mol}$ of $\mathrm{ClCH}_{2} \mathrm{COOH}$. In fact, the impact energy increased from 2.6 to $4.8 \mathrm{~kJ} / \mathrm{m}^{2}$, leading to an almost two-fold increase versus composites having unmodified wood flour. Generally, impact values of the unmodified wood flour exhibit voids formation and brittle fracture of the matrix, wood particles debonding, and pulling out of the polypropylene matrix. A higher concentration of monochloroacetic acid and sodium hydroxide in the wood flour leads to a weak interaction between the polypropylene matrix and wood filler, which supports the formation of a plastic deformation zone around the wood particles and an improved ductility of the polypropylene matrix. 


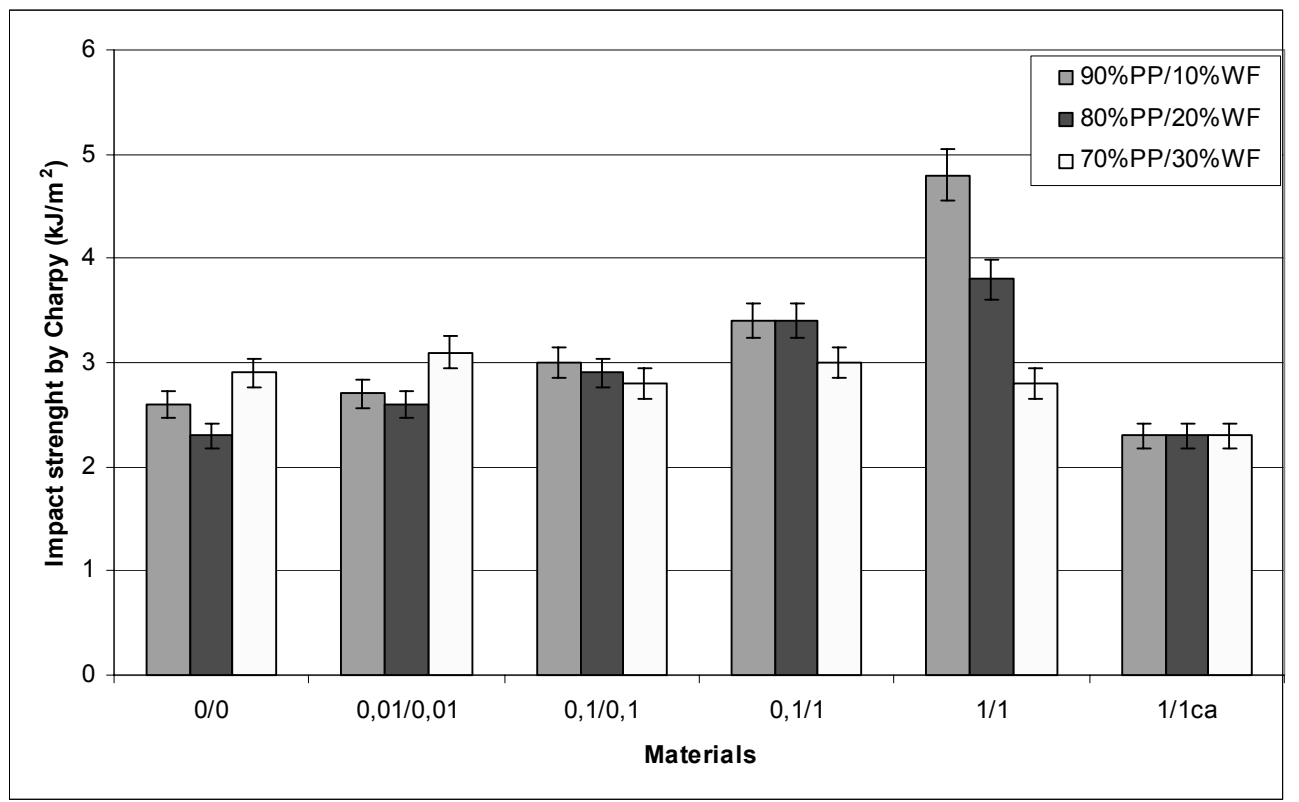

Fig. 1. Charpy notched impact strength of materials modified with different mole quantity $\mathrm{ClCH}_{2} \mathrm{COOH}$ and $\mathrm{NaOH}$. (0/0: $0 \mathrm{~mol} \mathrm{NaOH} / 0$ mol ClCH $\mathrm{COOH}_{2} \mathrm{CO}, 01 / 0,01: 0,01 \mathrm{~mol} \mathrm{NaOH} /$ $0,01 \mathrm{~mol} \mathrm{ClCH}_{2} \mathrm{COOH}, 0,1 / 0,1: 0,1 \mathrm{~mol} \mathrm{NaOH} / 0,1 \mathrm{~mol} \mathrm{ClCH}_{2} \mathrm{COOH}, 0,1 / 1: 0,1 \mathrm{~mol} \mathrm{NaOH} / 1 \mathrm{~mol}$ $\mathrm{ClCH}_{2} \mathrm{COOH}, 1 / 1: 1 \mathrm{~mol} \mathrm{NaOH} / 1 \mathrm{~mol} \mathrm{ClCH} \mathrm{COOH}_{2} \mathrm{COO}$ : $1 \mathrm{~mol} \mathrm{NaOH} / 1 \mathrm{~mol} \mathrm{ClCH} \mathrm{COOH}_{2}$ and $5 \%$ coupling agent)

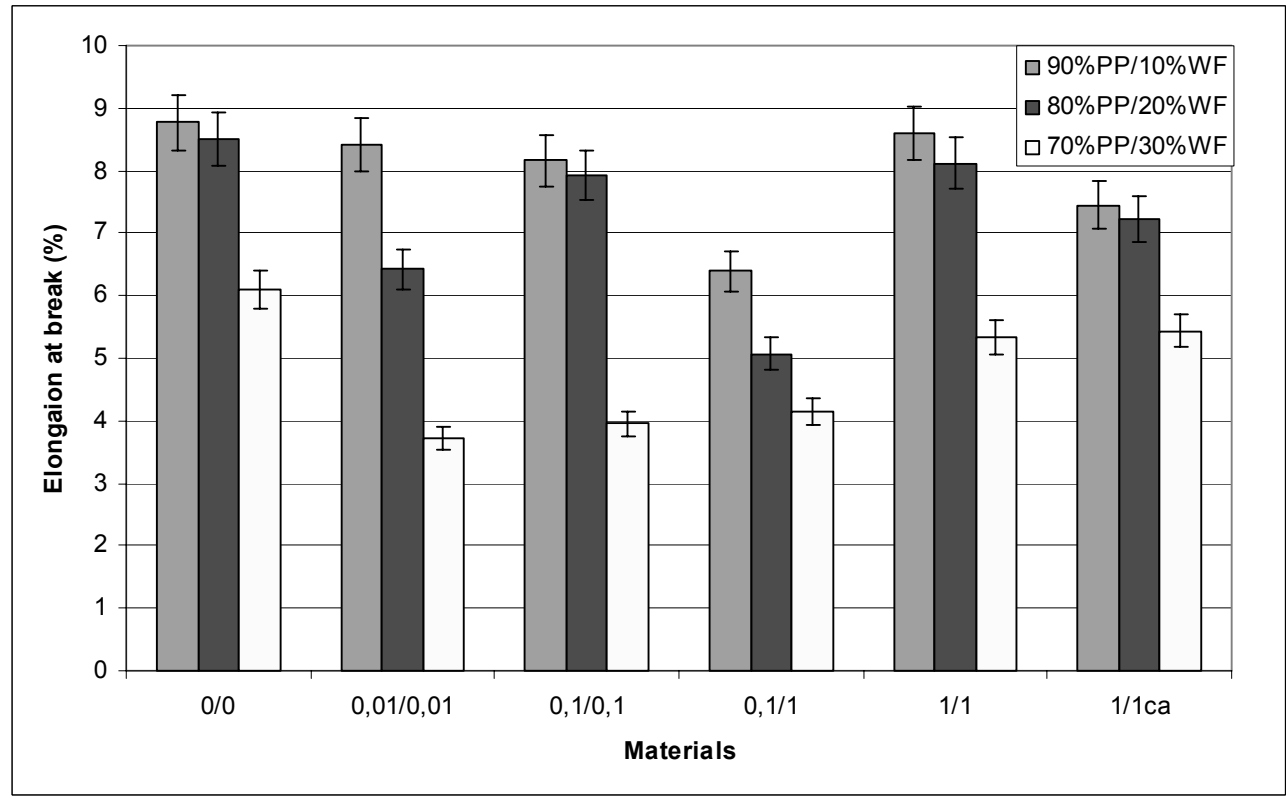

Fig. 2. The percent elongation at break of materials in percent modified with different mole quantities of $\mathrm{ClCH}_{2} \mathrm{COOH}$ and $\mathrm{NaOH}$. 
The tensile strength of the wood/filled composites decreased with increasing fraction of the wood flour mainly because of poor transfer of applied load through the interface. As a rule, fillers with higher stiffness than the matrix cause a dramatic decrease in the elongation at break (Oksman and Clemons 1998). The obtained results for the unmodified and modified polypropylene/wood flour composite are in accordance with the above mentioned rule (Fig. 2).

Fig. 3 shows the E-modulus (Elasticity modulus) of composites modified with different molar contents of modified agents. Flexural modulus is largely dependent on wood flour content in the composites. The E-modulus was improved with increase of wood flour concentration. The results suggest that wood flour can significantly enhance the stiffness of polypropylene composites.

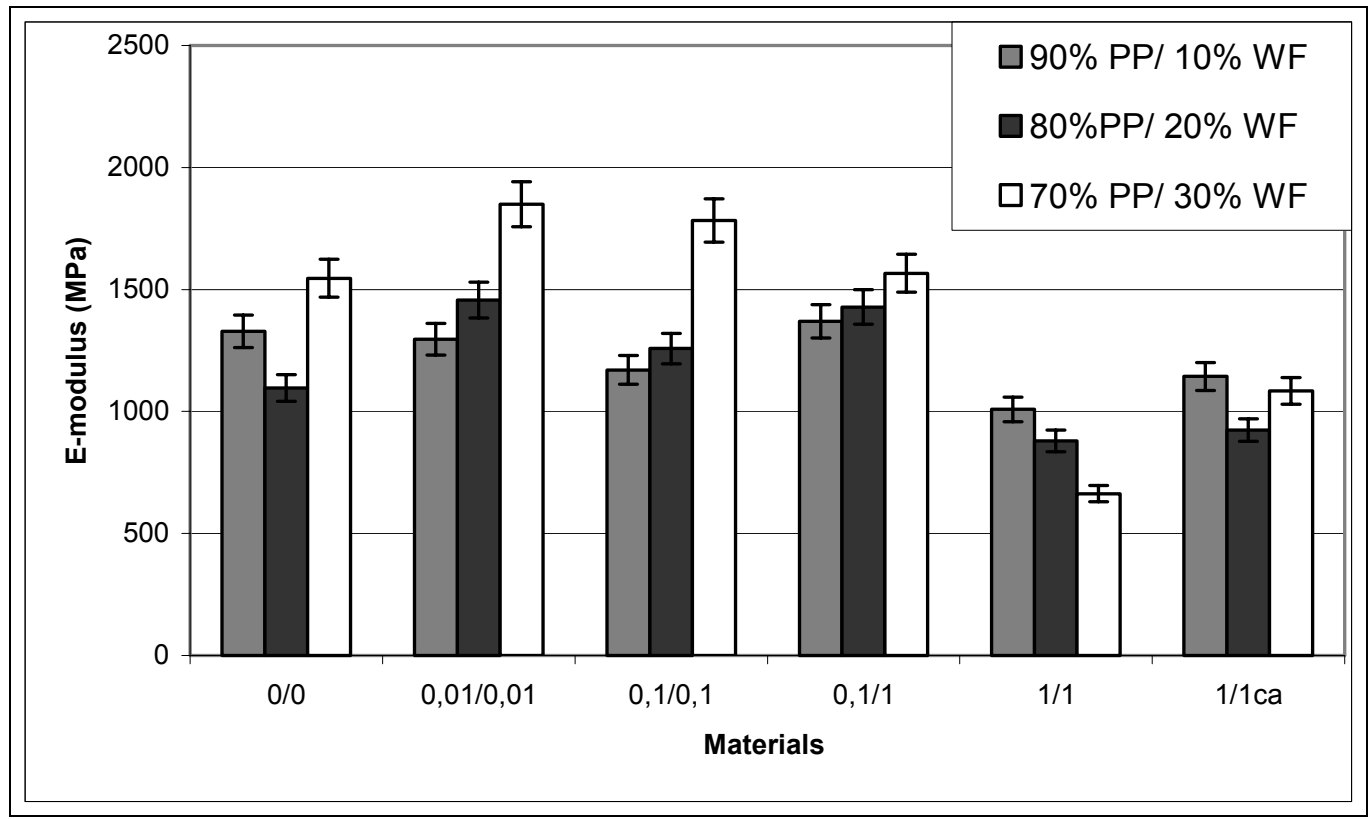

Fig. 3. E-Modulus of materials modified with different molar quantities of $\mathrm{ClCH}_{2} \mathrm{COOH}$ and $\mathrm{NaOH}$.

When modified with the maximum molar quantities of monochloroacetic acid and sodium hydroxide, the wood flour composites showed a large decrease of the E-modulus. It is much higher in the composites with lower quantities of modified agents $(0.01 \mathrm{~mol}$ $\mathrm{ClCH}_{2} \mathrm{COOH} / 0.01 \mathrm{~mol} \mathrm{NaOH}$ and $0.1 \mathrm{~mol} \mathrm{ClCH}_{2} \mathrm{COOH} / 0.1 \mathrm{~mol} \mathrm{NaOH}$ ), because the wood flour structure is not disordered and therefore the fiber character of the structure of the particle wood flour is retained.

Examination of the fracture surfaces of the composites by scanning electron microscopy gave information about how the modified agents influenced the morphology of the composite. Figures 4-6 illustrate how addition of wood flour to the polypropylene causes the formation of heterogeneous microstructures. The wood particle is not fractured and there are voids around the particle, indicating poor interaction between the wood surface and the polypropylene matrix. Lamellar structures, as they are typical for pure polypropylene, disappear (Fig. 5), and separated pieces of wood flour with size from 20 to $150 \mu \mathrm{m}$ are observed. The structure of polypropylene composites containing 30 
wt.- $\%$ wood flour modified with 1 mole $\mathrm{ClCH}_{2} \mathrm{COOH}$ and 1 mole $\mathrm{NaOH}$ is more homogeneous (Fig. 6) while homogenously dispersed wood flour particles in the size range of approximately $10 \mu \mathrm{m}$ from the second phase are observed. Good adhesion between the filler and matrix was also observed. The improved impact strength obtained by Charpy compared with composites filled with unmodified wood flour can be explained by better toughness of the matrix itself.

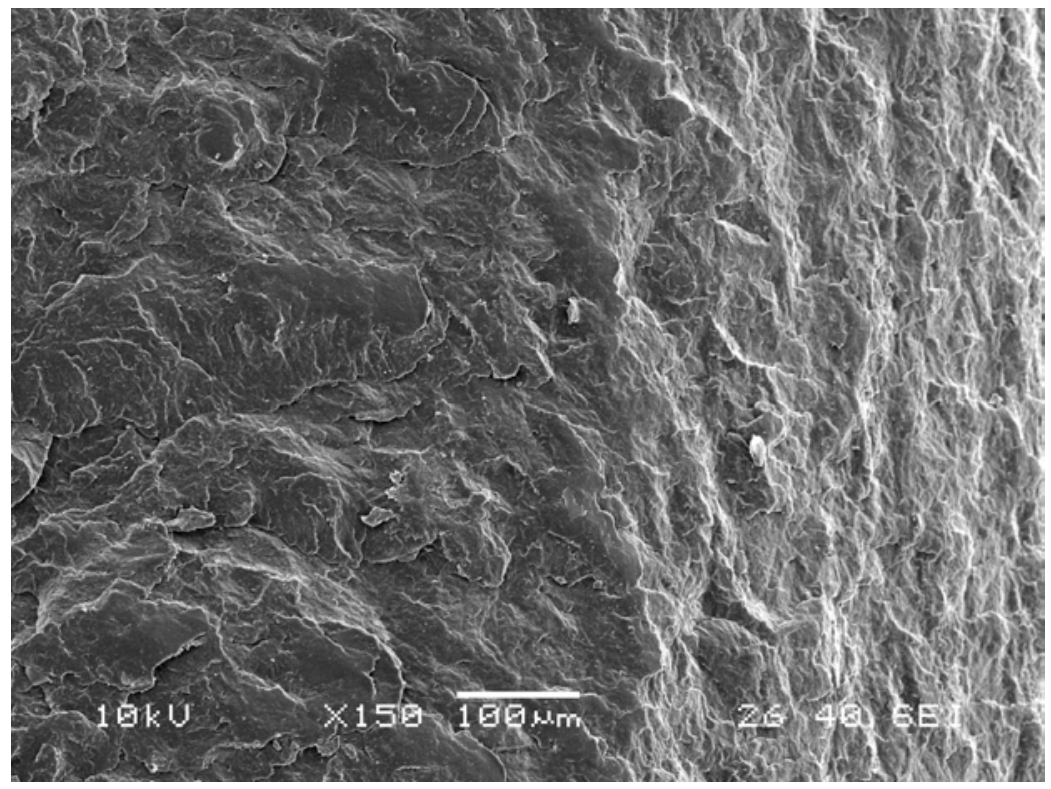

Fig. 4. Scanning electron micrograph of fracture surface of pure polypropylene.

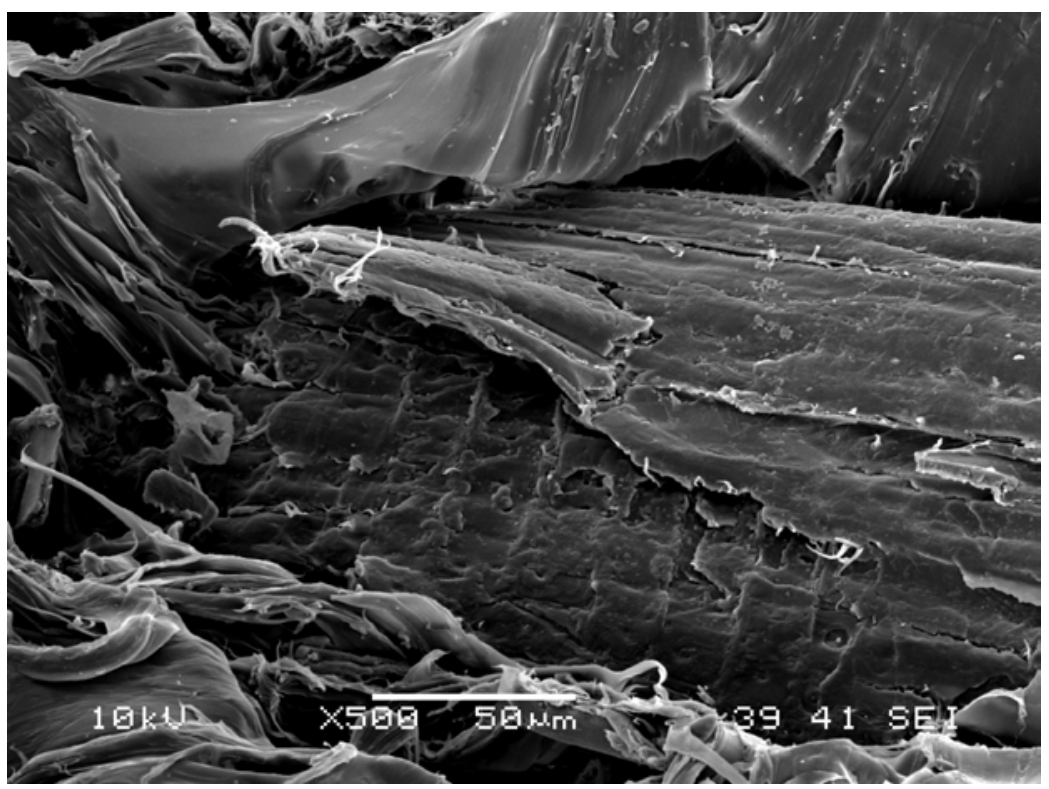

Fig. 5. Scanning electron micrograph of fracture surface of $70 \mathrm{wt} .-\%$ polypropylene/30 wt.- $\%$ unmodified wood flour. 


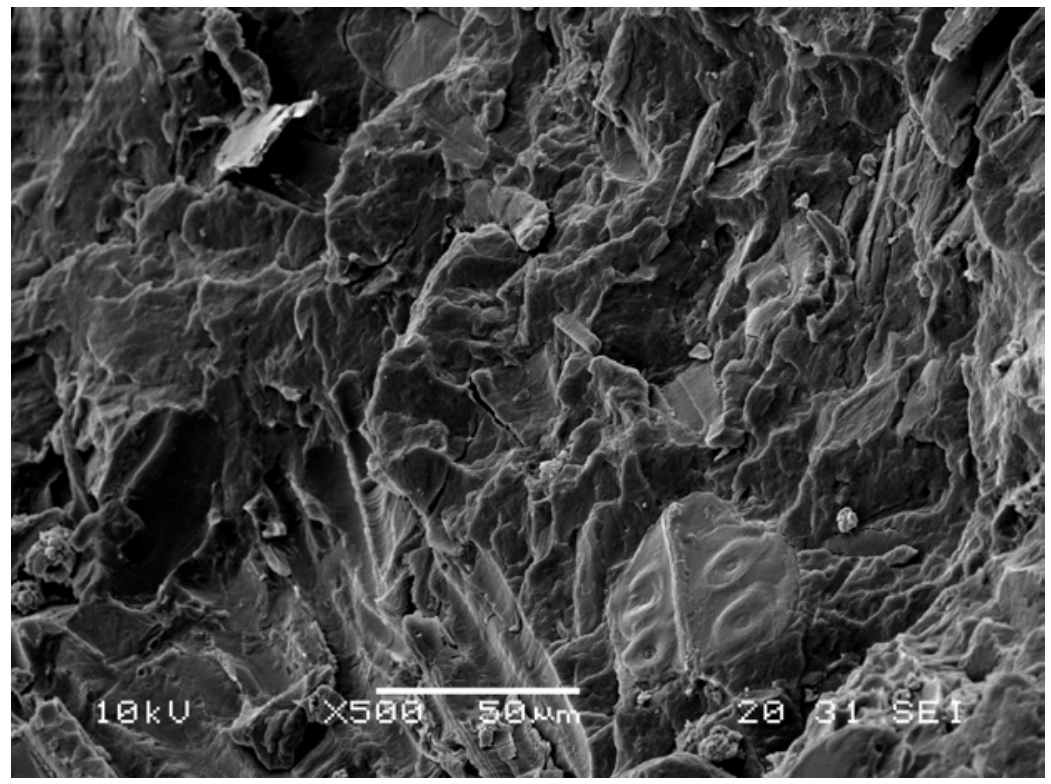

Fig. 6. Scanning electron micrograph of fracture surface of $70 \mathrm{wt} .-\%$ polypropylene/30 wt.- $\%$ modified wood flour with $1 \mathrm{~mol} \mathrm{ClCH}_{2} \mathrm{COOH}$ and $1 \mathrm{~mol} \mathrm{NaOH}$.

For the polypropylene with unmodified wood flour composite, a decreased crystallinity degree is observed, as well as the presence of separate globular formations. These results are in good agreement with the WAXS data, which will be discussed shortly. The polypropylene composites' samples with modified wood flour (Fig. 6) show an increasing tendency to an amorphous state and good ability for inclusion of wood flour particles in the matrix.

The results from WAXS analysis of polypropylene (Fig. 7A) are typical for standard polymer material with high crystallization degree. In the WAXS data of composites containing modified wood flour (Fig. 7C) the X-ray diffraction patterns of polypropylene are presented, but with a lower degree of diffraction intensity in combination with signals of remaining products of the modification reactions. The degree of crystallization of polypropylene and polymer composites with non-modified and modified wood flour was determined by using the Ruland/Vonk method (Table 1).

The X-ray diffraction data show that the addition of $10 \mathrm{wt} . \mathrm{-} \%$ wood flour in the polymer matrix simultaneously causes inversion in the intensity of polypropylene diffraction maxima and appearance of diffraction patterns of cellulose $11.3 \Theta^{\circ}$ (Fig. 7B). The diffraction maxima of cellulose for modified samples disappear from the diffraction pattern. The presence of modified wood flour leads to return of usual character of the diffraction patterns of polypropylene. This probably may be due to an improvement in the crystallization in the polypropylene or a more regular arrangement of macromolecules in polypropylene in the composite melts. This process could improve the homogeneous distribution of wood flour in the composite leading to significant improvement of some physical and mechanical parameters of the composites. 


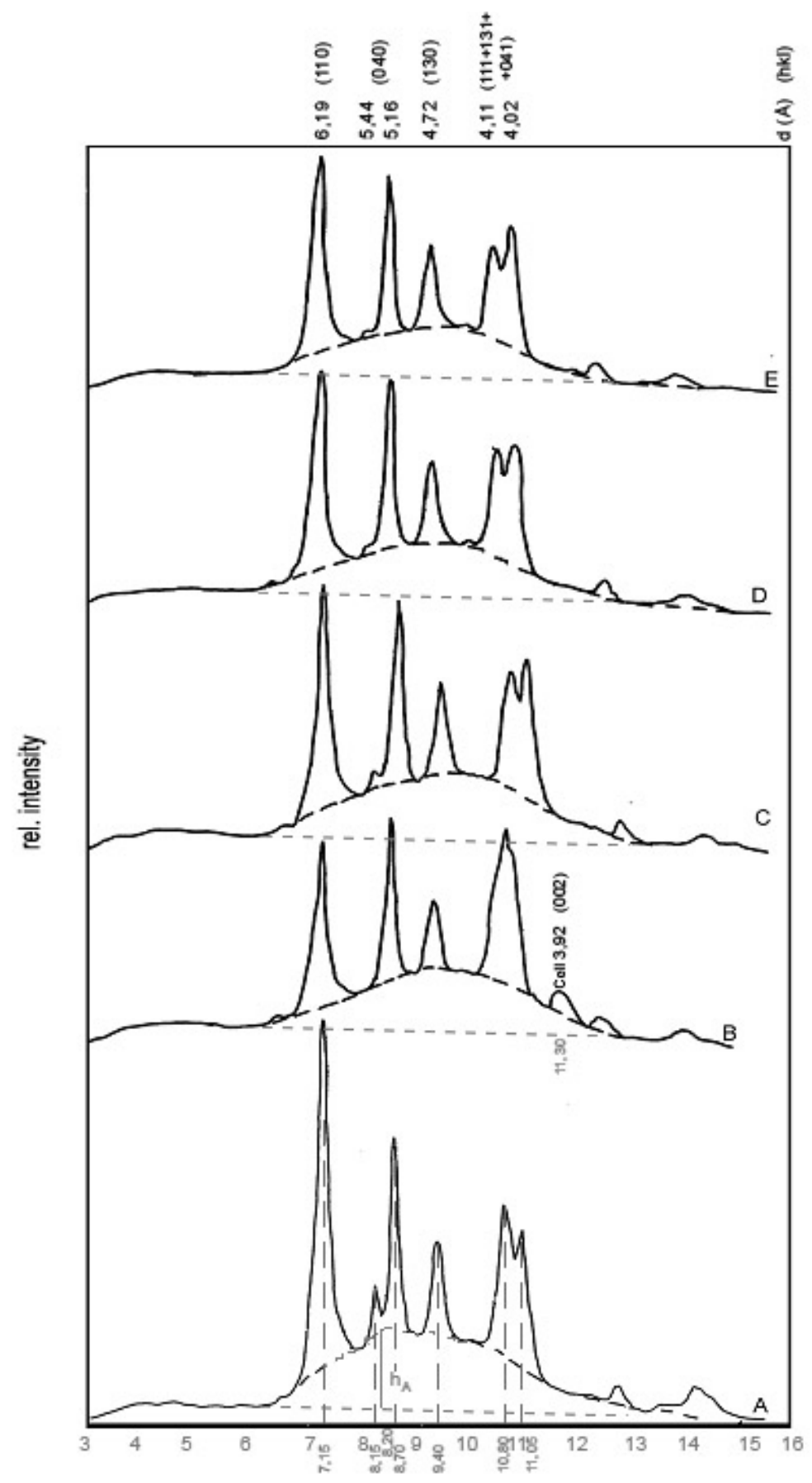

$\left(\theta^{\circ}\right)$

Fig. 7. WAXS of: A - polypropylene; B - polypropylene with $10 \%$ unmodified wood flour; C polypropylene with $10 \%$ wood flour modified with $0.01 \mathrm{~mol} \mathrm{ClCH} \mathrm{ClOH}_{2} \mathrm{COOH}$ and $0.01 \mathrm{~mol} \mathrm{NaOH}$; D - polypropylene with $10 \%$ wood flour modified with $0,1 \mathrm{~mol} \mathrm{ClCH}_{2} \mathrm{COOH}$ and $0.1 \mathrm{~mol} \mathrm{NaOH}$; E polypropylene with $10 \%$ wood flour modified with $1 \mathrm{~mol} \mathrm{ClCH}_{2} \mathrm{COOH}$ and $1 \mathrm{~mol} \mathrm{NaOH}$. 
Table 1. Crystallinity $\mathrm{x}_{\mathrm{c}}$ and Disorder Parameter $\mathrm{k}$

\begin{tabular}{|c|c|c|}
\hline Sample & $\underline{\mathbf{X}}_{\mathrm{c}}[\%]$ & $\underline{k}\left[10^{-2} \mathrm{~nm}^{2}\right]$ \\
\hline polypropylene & 39 & 1.8 \\
\hline wood flour & 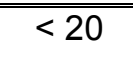 & - \\
\hline $90 \%$ polypropylene/10\% U wood flour & 28 & 1.6 \\
\hline $\begin{array}{c}90 \% \text { polypropylene/10\%WF/0.01 mol } \mathrm{ClCH}_{2} \mathrm{COOH} / 0.01 \\
\mathrm{~mol} \mathrm{NaOH}\end{array}$ & 32 & 1.6 \\
\hline 90\%PP/10\%WF/0.1 mol CICH${ }_{2} \mathrm{COOH} / 0.1 \mathrm{~mol} \mathrm{NaOH}$ & 35 & 1.7 \\
\hline $90 \% \mathrm{PP} / 10 \% \mathrm{WF} / 1 \mathrm{~mol} \mathrm{CICH} \mathrm{COOH}_{2} / 1 \mathrm{~mol} \mathrm{NaOH}$ & 37 & 1.7 \\
\hline
\end{tabular}

The absolute values for the crystallinity of polypropylene/wood flour-composites and polypropylene are not very reliable because the amorphous background scattering could not be measured due to the fact that no fully amorphous polypropylene sample was available. The amorphous background was calculated and not measured. The relative differences between the samples, however, are reliable while the pure wood flour phase has a low crystallinity of approximately less than $20 \%$.

\section{CONCLUSIONS}

1. Composite materials based on polypropylene and carboxymethylated wood flour were generated.

2. SEM and WAXS analysis demonstrated that the addition of non-modified wood flour degrades the homogeneity of the samples and decreases the crystallization degree of polypropylene.

3. The preliminary modification of wood flour with monochloroacetic acid influences the microstructure of the composites which then display an increasing tendency towards an amorphous state with good inclusion of the uniformly dispersed wood flour particles.

4. The polypropylene composites filled with modified wood flour do have a more homogeneous surface compared to polypropylene-unmodified wood flour composites.

5. In the presence of modified wood flour, the crystallization degree of polypropylene depends on the added quantity of the modification agent.

6. The process of structural homogenization improves the rheological properties of polypropylene composites in such a way that allows conventional production methods to still be employed. 


\section{REFERENCES CITED}

Albano, C., Poleo, R., Reyes, J., Ichazo, M., Gonzales, J., Brito, M. (2004). e-polymers No 022.

Bazarnova, N. G., Katrakov, I. B., and Markin, W. I. (2004). "Chemical modification of wood.” J. Ros. Cim. Ob-va im D. I. Mendeleeva. 15 (3), 108-115.

Coutinho, F. M. B., Costa, T. H. S., and Carvalho D. L. (2004). "Polypropylene-wood fiber composites: Effect of treatment and mixing conditions on mechanical properties." J. Appl. Polym. Sci. 65(6), 1227-1235.

Dobreva, D., Nenkova S., and Vasileva, St. (2005). "Investigation of the microstructure of polypropylene composites filled with wood flour modified with monochloracetic acid," NATO Science Ser. II 223, 177-180.

Dobreva, D., Nenkova, S., and Vasileva, St. (2004). "Modification of wood flour for polymer composites." Proceedings of the XVIII Congress of Chemists and Technologust of Macedonia. PPM-40.

Kishi, H., and Shiraiski N. (1986). "Wood-phenol adhesives prepared from carboxymethalated wood.” J. Appl. Polym. Sci. 32 (3), 3189-3209.

Hristov, V. N., Krumova, M., Vasileva, St., and Michler G .H. (2004). "Modified polypropylene wood flour composites. II. Fracture, deformation, and mechanical properties." J. Appl. Polym. Sci. 92(2), 1286-1292.

Michler, G. H. (1999). Polypropylene: An A-Z Reference. Dordrecht: Kluwer Publishers.

Marcovich, N. E., Reboredo, M. M., and Aranguren, M. I. (1998a). "Mechanical properties of woodflour unsaturated polyester pomposites." J. Appl. Polym. Sci. 70(11), 2121-2131.

Marcovich, N. E., Reboredo, M. M., and Aranguren, M. I. (1998b). "Dependence of the mechanical properties of woodflour-polymer composites on the moisture content." $J$. Appl. Polym. Sci. 68(13), 2069-2076.

Nunez, A. J., Sturm, P. C., Kenny, J. M., Aranguren, M. I., Marcovich, N. E., and Reboredo, M. M. (2002). "Mechanical characterization of polypropylene-wood flour composites.” J. Appl. Polym. Sci. 88(6), 1420-1428.

Oksman, K., and Clemons, G. (1998). "Mechanical properties and morphology of impact modified-wood flour polypropylene composites," J. Appl. Polym. Sci. 67(9), 15031513.

Park, B., and Balatinecz, J. (1997a). "Mechanical properties of wood-fiber/toughened isotactic polypropylene composites." Polym. Comp. 18(1), 79-89.

Park, B., and Balatinecz, J. (1997b). "A comparison of compounding processes for woodfiber/termoplastic composites." Polym. Comp. 18(3), 425-431.

Qiu, W., Zhang, F., Endo, T., and Hirotsu, T. (2005). "Effect of maleated polypropylene on the performance of polypropylene/cellulose composite." Polym. Comp. (26), 448.

Ruland, W. (1961). "X-ray determination of crystallinity and diffuse disorder scattering." Acta Cryst. (14), 1180-1185.

Shibata, S., Cao, Y., and Fukumoto, I. (2005). "Effect of bagasse fiber on the flexural properties of biodegradable composites." Polym. Comp. 26(5), 689-964.

Tacterajvidi, M., and Ebrahimi, G. (2003). "Water uptake and mechanical characteristics of natural filler-polypropylene composites.” J. Appl. Polym. Sci. 88(4), 941-946. 
Tan, X., and Yu, Q. (1997). "Study on carbomethylating modification of wood and its solubility." Chemistry and Industry of Forest Products. 17 (3), 33-39.

Thielemans, W., and Wool, R. (2005). "Kraft lignin as fiber treatment for natural fiberreinforced composites.” Polym. Comp. 26(5), 695-705.

Toriz, G., Denes, F., Ramos, J., and Young, R. A. (2001). "Woodfiber-plastic composites," Proceedings of the Forest Products Society. Madison. WI. 2001, 207221.

Toriz, G., Denes, F., and Young, R. A. (2002). "Lignin-polypropylene composites. Part 1: Composites from unmodified lignin and polypropylene." Polym. Comp. 23(5), 806813.

Toriz, G., Ramos, J., and Young, R. A. (2004). "Lignin-polypropylene composites. II. Plasma modification of kraft lignin and particulate polypropylene." J. Appl. Polym. Sci. 91(3), 1920-1926.

Wu, J., Yu, D., Chan, C., Kim, J., and Mai, Y. (2000). "Effect of fiber pretreatment condition on the interfacial strength and mechanical properties of wood fiber/polypropylene composites.” J. Appl. Polym. Sci. 76(7), 1000-1010.

Article submitted: July 13, 2006; Revision accepted: Sept. 20, 2006; Published: Sept. 22, 2006. 